\title{
Experimental Conditions for Nitrate Reduction by Certain Strains of the Genus Lactobacillus
}

\author{
By M. ROGOSA \\ National Institute of Dental Research, National Institutes of Health, Public Health \\ Service, U.S. Department of Health Education and Welfare, Bethesda, Maryland, \\ U.S.A., and the National Institute for Research in Dairying, \\ University of Reading, England
}

(Received 14 October 1960)

\section{SUMMARY}

Costilow \& Humphreys's (1955) observation that certain strains of Lactobacillus plantarum reduced nitrates under certain conditions was confirmed. Two strains of L. fermenti also reduced nitrates. In static culture, agar and anaerobiosis were not essential for nitrate reduction, contrary to speculations in the literature. Nitrate reduction was possible only in media with restricted carbohydrate and with the $\mathrm{pH}$ value maintained at a relatively high value within the activity range of nitrate reductases. For good growth, lactobacilli for the nitrate test have been customarily grown in media with high carbohydrate content, with consequent low final $\mathrm{pH}$ values. This seems to be the essential reason why the genus Lactobacillus had previously been defined as unexceptionally nitratase-negative.

\section{INTRODUCTION}

Until recent years the genus Lactobacillus has been described as unable to reduce nitrates (Bergey's Manual, 1948; Rogosa et al. 1953). However, Costilow \& Humphreys (1955) reported that 18 of 38 strains of Lactobacillus plantarum reduced nitrates. This result was achieved through the use of the BBL indole-nitrite medium (Baltimore Biological Laboratory, Inc.) which has an initial $\mathbf{p H}$ value of $\mathbf{7 \cdot 2}$ and a composition of $2 \%$ (w/v) Trypticase, $0.2 \%(\mathrm{w} / \mathrm{v}) \mathrm{Na}_{2} \mathrm{HPO}_{4}$, and $0.1 \%(\mathrm{w} / \mathrm{v}$ ) each of glucose, $\mathrm{KNO}_{3}$ and agar. Negative results, consistent with earlier general experience, were obtained with broth media, such as the BBL indole-nitrite medium minus agar, or Difco nitrate broth. To explain this, Costilow \& Humphreys (1955) reasoned that agar would tend to decrease the oxygen tension of the medium and stated: 'It is obvious that the oxygen tension of the medium was the most important factor in nitrate reduction...' From inspection of the formula of the $\mathrm{BBL}$ indole-nitrite medium it is evident that it contains very little fermentable carbohydrate $(0 \cdot 1 \%, \mathrm{w} / \mathrm{v})$ and is very highly buffered. Also the initial $\mathrm{pH}, \boldsymbol{7 \cdot 2}$,

- is high. This suggests that nitrate reduction may be a function of $\mathrm{pH}$ value and that the nitrate reductase enzymes may have a relatively high and narrow $\mathrm{pH}$ activity range. For example, Woods (1938) found with Clostridium relchii that, when the reduction rate at $\mathrm{pH} 6.8$ was taken as $100 \%$, it was $50 \%$ at $\mathrm{pH} 6.4$ and only $10 \%$ at $\mathrm{pH} 6 \cdot 1$ after $25 \mathrm{~min}$. After $35 \mathrm{~min}$., the reduction rate decreased further at $\mathrm{pH} 6.5$ to only $10 \%$. Similar results were obtained with a strain of 
Escherichia coli. Nason \& Evans (1955) studied a purified enzyme from Neurospora crassa which catalysed the reaction $\mathrm{TPNH}+\mathrm{H}^{+}+\mathrm{NO}_{3}^{-} \rightarrow \mathrm{TPN}^{+}+\mathrm{NO}_{2}^{-}+\mathrm{H}_{2} \mathrm{O}$ and the enzyme exhibited a sharp optimum for activity at $\mathrm{pH} 7 \cdot 0$ in phosphate buffer. Zucker \& Nason (1955) found maximum activity between $\mathrm{pH} 8.0$ and $\mathbf{9 \cdot 0}$ for the intermediate enzyme, hydroxylamine reductase, in denitrification by $N$. crassa. Najjar (1955) obtained similar high $\mathrm{pH}$ optima with Pseudomonas stutzeri and Bacillus subtilis for the enzymic conversion of $\mathrm{NO}_{2}^{-}$and $\mathrm{NO}$ to $\mathrm{N}_{2}$. Because of the importance of nitrate reduction as a taxonomic criterion, a wide range of Lactobacillus species, and certain streptococci and pediococci, were tested in experiments designed to discover the appropriate conditions for nitrate reduction.

\section{METHODS}

The strains of lactobacilli were representative of 13 species in the collection of Dr M. Elisabeth Sharpe (National Institute for Research in Dairying, NIRD, University of Reading), obtained through original isolations by Dr Sharpe or other workers, and from such culture colleetions as the American Type Culture Collection (ATCC), the (British) National Collection of Type Cultures (NCTC), the (British) National Collection of Industrial Bacteria (NCIB) and the (British) National Collection of Dairy Organisms (NCDO maintained at NIRD). Each strain had been carefully studied by numerous tests (Rogosa et al. 1953; Rogosa \& Sharpe, 1959) including serological procedures (Sharpe, 1955) wherever specific group antisera could be prepared.

There were strains of Lactobacillus plantarum. The origins of the following 7 are of interest: $A R 1$ NIRD 17/5;P4, NCTC 6376 from ATCC 8014; P 16, ATCC 8014; $A R$ 5, L. arabinosus V743 Tittsler; $P$ 30, V 322 Tittsler; $P$ \%, NIRD 1-4; $P$ 8, NIRD 1-8. Strains $A R 1, P 4, P 16$ and $A R 5$ are identical and are really only a single strain designated L. arabinosus $17 / 5$ by Fred, Peterson \& Anderson (1921), but ascribed different numbers in different culture collections.

Five strains of Lactobacillus fermenti were tested. Strain $F 1$ is identical with ATCC 9338 and NCTC 6991, and strain F4 is NCTC 7230.

The remaining strains were distributed numerically as follows: Lactobacillus acidophilus, $5 ;$ L. brevis, $10 ;$ L. buchneri, $1 ;$ L. bulgaricus, $9 ;$ L. casei, $14 ;$ L. cellobiosus, 2 ; L. delbrueckii, 2 ; L. helveticus, 1 ; L. jugurti, $3 ;$ L. lactis, 11 ; L. leichmannii, $2 ;$ L. salivarius, 4.

In addition, one strain each of the following group D streptococci was tested: Streptococcus bovis, S. durans, S. faecalis var. liquefaciens, $S$. faecalis and $S$. faecium. Among group $\mathrm{N}$ streptococci were two strains of $S$. cremoris, one of $S$. lactis and two of $S$. lactis var. diacetilacticus. Three strains of Pediococcus cerevisiae, including ATCC 8081, were also tested.

The media used were: (1) the BBL indole-nitrite medium; (2) Difco nitrate broth; (3) various modifications of these such as the addition of agar, yeast extract, increased buffering with $\mathrm{Na}_{2} \mathrm{HPO}_{4}$, and changes in the concentration of glucose. The conditions for each experiment will be described in the tabulation of results.

Cultures were inoculated with one drop from good growth in MRS broth (de Man, Rogosa \& Sharpe, 1960) and incubated for 6-7 days at $37^{\circ}$ except for Lactobacil- 
lus plantarum, L. brevis, L. casei, the streptococci and the pediococci which were incubated at $30^{\circ}$.

When anaerobiosis was desired it was obtained by using McIntosh \& Fildes jars filled with either $\mathrm{H}_{2}$ or a $90 \% \mathrm{H}_{2}+10 \%(\mathrm{v} / \mathrm{v}) \mathrm{CO}_{2}$ mixture, and combining residual traces of $\mathrm{O}_{2}$ with $\mathrm{H}_{2}$ by using the electrically heated catalyst.

The reagents for the detection of nitrite were: solution 1 containing $2 \mathrm{~g}$. sulphanilic acid in $250 \mathrm{ml}$. $5 \mathrm{~N}$-acetic acid; solution 2 containing $1.5 \mathrm{ml}$. dimethyl- $\alpha$-naphthylamine in $250 \mathrm{ml}$. $5 \mathrm{~N}$-acetic acid. The latter reagent was recommended by Wallace $\&$ Neave (1927) and Tittsler (1930) as superior to the $\alpha$-naphthylamine reagent because the colour develops instantaneously, is more intense, and does not fade in a reasonable period of time. For the nitrite test, one drop of culture was deposited in a white porcelain spot plate followed by one drop each of solutions 1 and 2 . The pink to red colour in positive tests developed at once and was unequivocal. The spot plate technique was often superior to tests made directly in the tubes. Some media contain substances (thioglycollate, for example) which inhibit colour development, but with the quantities of culture and reagents described for the spot plate test, colour development was uninhibited. Negative controls on the media and a positive control with Micrococcus aureus, phage type 80 , were included routinely. All negative tests were confirmed by reducing residual nitrate to nitrite with $\mathrm{Zn}$ dust on the spot plate and testing for nitrite as described. $\mathrm{Zn}$ reductions in the tubes often gave ambiguous and false results.

\section{RESULTS}

The only species in which some strains reduced nitrates were Lactobacillus plantarum ( 7 of 12) and L. fermenti ( 2 of 5 tested). All other species of lactobacilli, and the streptococci and pediococci examined, were unable to reduce nitrates under any of the experimental conditions. Thus, Costilow \& Humphreys's (1955) observation that certain strains of $L$. plantarum can reduce nitrates under appropriate conditions was confirmed.

Some typical data from experiments concerning the role of agar, yeast extract, initial $\mathrm{pH}$ and anaerobiosis in nitrate reduction by Lactobacillus plantarum, are presented in Table 1. When Difco nitrate broth (DNB) or DNB supplemented with agar and yeast extract was used at an initial $\mathrm{pH} 6.4$ (a $\mathrm{pH}$ value favourable for growth) all strains repeatedly failed to reduce nitrates aerobically or anaerobically and the $\mathrm{pH}$ value decreased sharply to a final value of 3.4. At the relatively unfavourable value $\mathrm{pH} 7 \cdot \mathbf{4}$, however, the cultures reduced nitrates, the $\mathrm{pH}$ decrease was markedly less, and the final $\mathrm{pH}$ value was about $6 \cdot 4$, i.e. 3 units less than the decrease obtained when the initial value was $\mathrm{pH} 6 \cdot 4$.

In BBL indole-nitrite (IN) medium nitrate reduction was sometimes suppressed under anaerobic conditions, as illustrated by the data for strain P30. In IN medium supplemented with Difco yeast extract (YE) nitrate reduction was also occasionally absent or weak. From observation of growth it was obvious that these weak or negative responses were related to total growth and that growth in IN medium $+\mathrm{YE}$ was even poorer than in the relatively poor IN medium. Also, it is clear from Table 1 that nitrate reduction, both aerobically and anaerobically, took place in the absence of agar, which was irrelevent to the process. Yeast extract in broth media, 
404

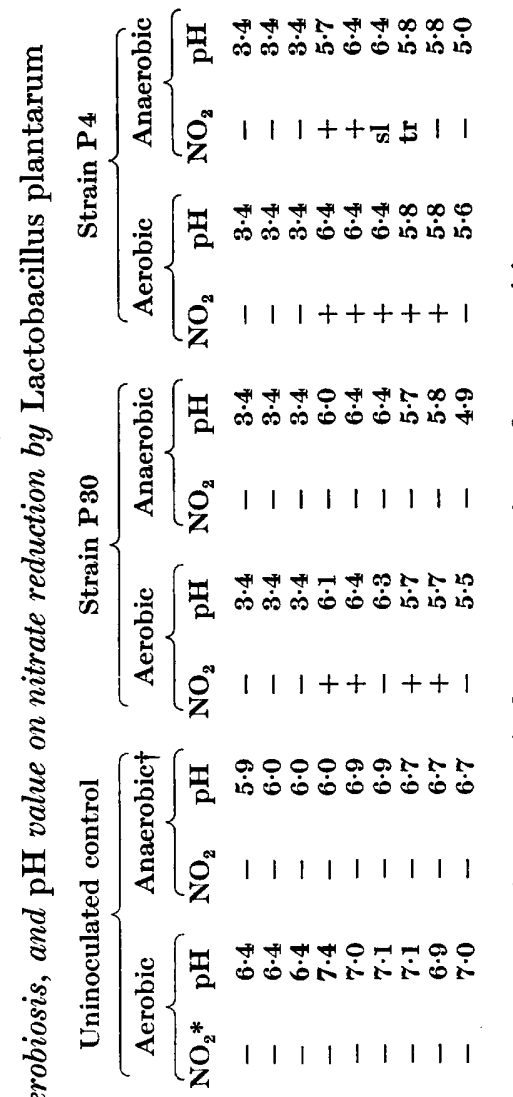

b

:

3

$\sum_{\mathbb{N}}^{\mathbb{8}}$

ำ
M. Rogosa

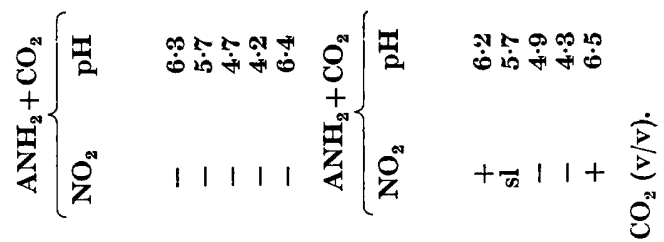

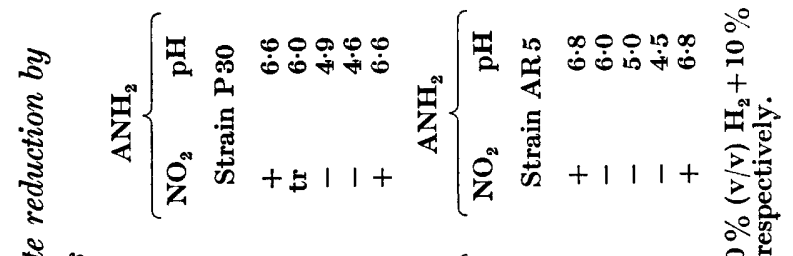

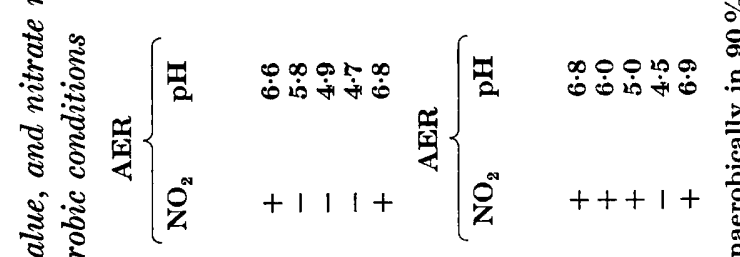

范要

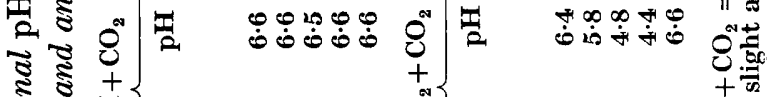

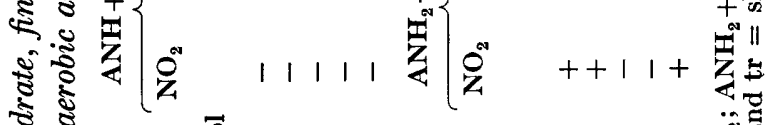

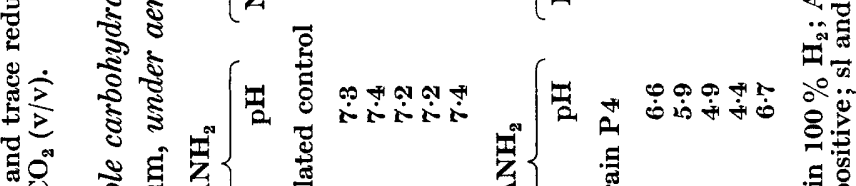

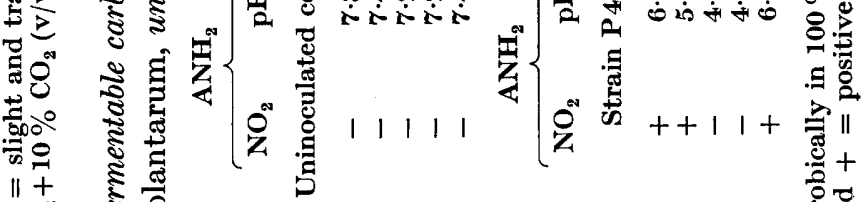

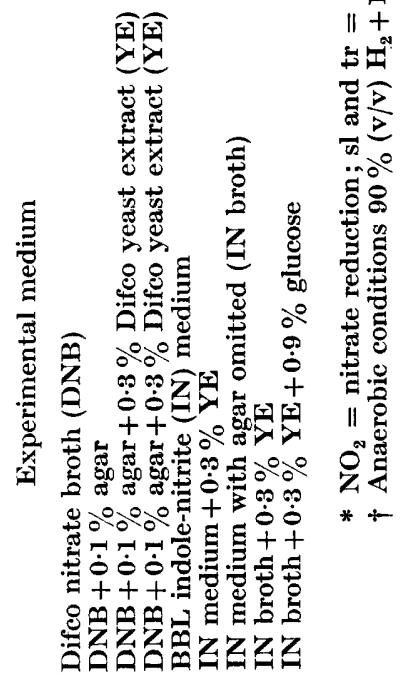

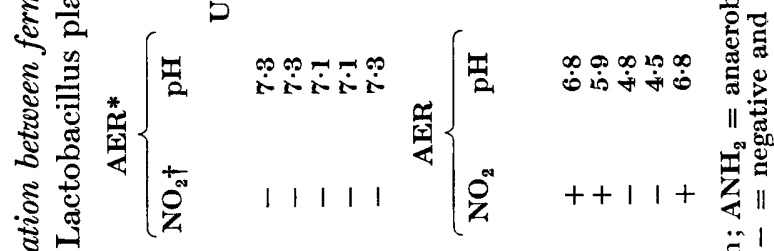

:

峟峞:

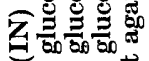

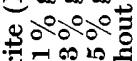

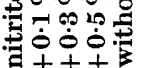

응 छ

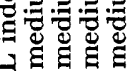

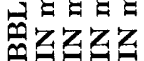

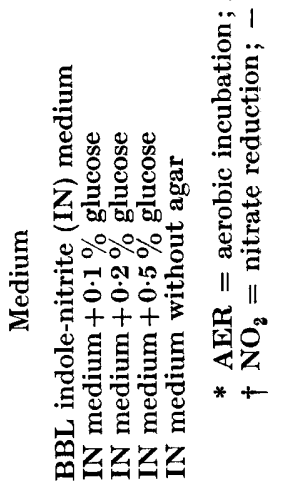


contrary to the experience with agar-containing media, did not inhibit nitrate reduction. What is most germane to this discussion is that cultures in media such as IN medium without agar + YE supplemented with conventional quantities of glucose $(0.9 \%, \mathrm{w} / \mathrm{v})$, had relatively low terminal $\mathrm{pH}$ values and also did not then reduce nitrates.

The above results strongly indicate that induced anaerobic conditions, yeast extract, and agar are not essential for nitrate reduction by these strains. Rather, it appears that the $\mathrm{pH}$ value, fermentable carbohydrate, and buffer capacity are the principal factors which effect nitrate reduction. Table 2 presents typical data which confirm this hypothesis. Anaerobiosis previously was achieved with $90 \%$ (v/v) $\mathrm{H}_{2}+10 \%(\mathrm{v} / \mathrm{v}) \mathrm{CO}_{2}$. Since $\mathrm{CO}_{2}$ may decrease the $\mathrm{pH}$ value of the medium, anaerobiosis in further experiments was also maintained by an atmosphere of $100 \% \mathrm{H}_{2}$. As little as $0 \cdot 1 \%(\mathrm{w} / \mathrm{v})$ added glucose inhibited nitrate reduction by Lactobacillus plantarum $\mathbf{P} 30$. Nitrate reduction by this strain seemed most sensitive to slight acidity from the fermentation of glucose, but all nitrate positive strains in IN medium were, with one exception, unable to reduce nitrates when $\mathbf{0 . 3} \%(\mathrm{w} / \mathrm{v})$ glucose was added and the $\mathrm{pH}$ value consequently decreased to $\mathbf{5 \cdot 0}$ or less. With $0.5 \%(\mathrm{w} / \mathrm{v})$ glucose, nitrate reduction was never observed. Again, positive reactions were generally fewer or less intense in anaerobic as compared with aerobic cultures, and it is quite clear that agar had no enhancing effect. These repeated results with agar do not agree with those of Costilow \& Humphreys (1955). In experiments which repeated their experimental protocol exactly as described, but in which the $\mathrm{pH}$ values of comparable broth and agar media were adjusted electrometrically exactly to the same initial value of $7 \cdot 1$, there was no difference in nitrate reduction in broth or agar containing media.

The strain of Micrococcus aureus, phage type 80 , which was used as a positive control, reduced nitrate to nitrite at $\mathrm{pH} 7 \cdot 0$. But at $\mathrm{pH} 7 \cdot 5$ or above the organism consistently also reduced nitrite completely, with accumulation of $\mathbf{N}_{\mathbf{2}}$. In this case it would appear that the nitrite reductase enzyme had an even higher $\mathrm{pH}$ activity range than the nitrate reductase.

\section{DISCUSSION}

Clarke (1959) emphasized the nitrate reducing property of some anaerobic bifid organisms named Lactobacillus bifidus. In the judgement of the writer and of Orla-Jensen, Orla-Jensen \& Winther (1936), Rogosa \& Sharpe (1959), and Sundman, Bjorksten \& Gyllenberg (1959) who described these organisms as 'organisms previously incorrectly designated Lactobacillus bifidus', these organisms should not be properly within the genus Lactobacillus but rather be allocated elsewhere. A more extensive discussion is reserved for the future.

The plausible argument that anaerobic technique is essential for nitrate reduction in static culture is not new. ZoBell (1932), in a study of nitrate reduction by Brucella spp., advocated the use of a medium made semisolid with $0.3 \%(w / v)$ agar, which he thought would lower the $\mathbf{O} / \mathbf{R}$ potential and thus encourage nitrate reduction. The basal medium was a poor one containing only $0 \cdot 2 \%(\mathrm{w} / \mathrm{v})$ peptone, $0 \cdot 1 \%(\mathrm{w} / \mathrm{v})$ beef extract, and $0.3 \% \mathrm{NaCl}(\mathrm{w} / \mathrm{v})$ as nutrients. He observed markedly improved growth in the semisolid medium. In the absence of comparative aerobic and 
anaerobic results in broth media it is just as reasonable to assume that the agar was exerting nutritional effects or was adsorbing toxic materials.

It has already been shown in the present experiments that agar and anaerobic cultivation are unessential for nitrate reduction by Lactobacillus plantarum. The statement by Costilow \& Humphreys (1955) 'that oxygen tension is a very important factor in the ability of bacteria to reduce nitrates' and their remarks concerning Sacks \& Barker (1949) can be misunderstood. Sacks \& Barker (1949) said: 'Weissenberg (1897) tested the ability of three denitrifying bacteria to reduce nitrate and nitrite in shallow layers of medium exposed to air and in the complete lack of oxygen. Weissenberg found that complete denitrification occurred in the anaerobic cultures, whereas aerobically nitrate was reduced only as far as nitrite.' (Italics mine.) Sacks \& Barker proceeded to test the effect of different partial pressures of oxygen on denitrification by Pseudomonas denitrificans, using special precautions to maintain equilibrium between the atmosphere and the culture medium. This was done in manometric experiments by shaking the flasks at the rapid rate of 150 oscillations/ min. Under these conditions both nitrate and nitrite reduction were inhibited.... 'but even in a solution fully saturated with air the rate of nitrate reduction is 29 per cent of the anaerobic rate'. The influence of oxygen tension on the formation of nitrate- and nitrite-reducing enzyme systems during growth was determined in experiments in which the bacteria were grown anaerobically 'and aerobically while being vigorously aerated with $1 \cdot 0,5 \cdot 0$, or $20 \cdot 6$ per cent oxygen in nitrogen'. It was found that: 'The formation of nitrite-reducing enzymes is decreased 29 per cent by 1 per cent oxygen and is completely prevented by oxygen at a level of 5 per cent or higher. The lowest oxygen level capable of preventing the formation of nitritereducing enzymes may be considerably below 5 per cent; no data are available in the range between 1 and 5 per cent oxygen. The formation of nitrate-reducing enzymes is much less sensitive to oxygen during growth; 1 per cent oxygen causes no detectable inhibition and even saturation of the culture medium with air does not completely prevent the formation of such enzymes.' (Italics mine.) Furthermore, at an oxygen tension of $5 \%$ when nitrite reduction was nil, nitrate reduction was still $65 \%$ of the anaerobic reaction.

The usual conditions for the nitrate-reduction tests are static cultures, not 'aerobically while being vigorously aerated'. Also, negative oxidation-reduction potentials are reached by lactic acid bacteria in carbohydrate media during early 'aerobic' growth (Frazier \& Whittier, 1931). It seems highly probable that the deleterious effect of oxygen on nitrate reduction has not been clearly differentiated from its effect on nitrite reduction and that an argument has been applied from the inapplicable case of denitrifying bacteria which reduce nitrates to nitrites and then reduce nitrites to other products. But in the routine test for nitrate-reduction the reagents test for nitrite accumulation. Even with denitrifying bacteria which also reduce nitrite, the disappearance of nitrite and residual nitrate indicates a positive reaction.

Some years ago the writer's laboratory tested hundreds of lactobacilli for nitrate reduction in anaerobic culture with completely negative results. Included were many strains of Lactobacillus plantarum, among which were some that were positive when tested later by Costilow \& Humphreys (1955). These have also been found to reduce nitrate in the present work. Thus, the argument which involves decreased 
oxygen tensions was not appealing in itself as an explanation for previous negative results. We have seen that the reaction of the medium is a critical factor in the reduction of nitrates. Generally, nitrate media for denitrifying bacteria contain extremely little added carbohydrate or more often none at all. It is not difficult to see now that with the acidogenic lactobacilli relatively small concentrations of fermentable carbohydrate may inhibit or prevent nitrate reduction because of $\mathrm{pH}$ changes. It has previously been customary to culture lactobacilli for the nitrate test in media containing enough carbohydrate for good growth. With the accumulation of acidic fermentation products the $\mathrm{pH}$ value, even in early growth, shifts beyond the activity range of nitrate reductases. This seems the highly probable reason why the genus Lactobacillus has previously been described as unexceptionally nitrate-negative.

It is not clear why only certain strains of Lactobacillus plantarum and L. fermenti were nitrate-positive. There were no obvious correlations between this and any other properties of the organisms. Most species grew poorly in the media tried. Attempts to improve growth by the use of massive inocula of washed organisms or to induce adaptation, and changes in the buffer content of media, have not yet changed the nitrate-negative character of any organisms.

I gratefully acknowledge the hospitality of the Director and staff of the National Institute for Research in Dairying, University of Reading, England, where most of this work was done. Particularly I acknowledge the kind help of Dr M. Elisabeth Sharpe who provided me with laboratory facilities, technical aid and many cultures.

\section{REFERENCES}

Bergey's Manual of Determinative Bacteriology (1948). 6th ed. Ed. R. S. Breed, E. G. D. Murray \& A. P. Hitchins. Baltimore: Williams and Wilkins.

Clarke, R. T. J. (1959). A dextran-fermenting organism from the rumen closely resembling Lactobacillus bifidus. J. gen. Microbiol. $20,549$.

Costrlow, R. N. \& Humphreys, T. W. (1955). Nitrate reduction by certain strains of Lactobacillus plantarum. Science, $121,168$.

Frazier, W. C. \& Whitrier, E. O. (1931) Studies on the influence of bacteria on the oxidation-reduction potential of milk. I. Influence of pure cultures of milk organisms. J. Bact. 21, 239.

Fred, E. B., Peterson, W. H. \& Anderson, J. A. (1921). The characteristics of certain pentose-destroying bacteria, especially as concerns their action on arabinose and xylose. J. biol. Chem. 48, 385.

Man, J. C. De, Rogosa, M. \& Sharpe, M. E. (1960). A medium for cultivation of lactobacilli. J. appl. Bact. 23, 130.

NaJJAR, V. A. (1955). Nitrite metabolism. Enzymatic formation of nitrogen gas $\left(\mathrm{N}_{2}\right)$ from nitrite and nitric oxide gas (NO). Formation of nitric oxide gas from nitrite. In Methods of Enzymology, 2, 420. Ed. S. P. Colowick \& N. O. Kaplan. New York: Academic Press Inc.

Nason, A. \& Evans, H. J. (1955). Nitrate reductase from Neurospora. In Methods in Enzymology, 2, 411. Ed. S. P. Colowick \& N. O. Kaplan. New York: Academic Press Inc.

Orla-Jensen, S., Orta-Jensen, A. D. \& Winther, O. (1936). Bacterium bifidum und Thermobacterium intestinale. Zbl. Bakt. (II. Abt.), 93, 321.

Rogosa, M., Wiseman, R. F., Mitchell, J. A., Disraely, M. \& Bearman, A. J. (1953). Species differentiation of oral lactobacilli from man including descriptions of Lactobacillus salivarius nov.spec. and Lactobacillus cellobiosus nov.spec. J. Bact. 65, 681. 
Rogosa, M. \& Sharpe, M. E. (1959). An approach to the classification of the lactobacilli. J. appl. Bact. 22, 329.

Sacks, L. E. \& Barker, H. A. (1949). The influence of oxygen on nitrate and nitrite reduction. J. Bact. 58, 11.

Sharpe, M. E. (1955). Serological classification of lactobacilli. J. gen. Microbiol. 12, 107.

Sundman, V., Buörkstein, K. \& Gyllenberg, H. G. (1959). Morphology of the bifid bacteria (organisms previously incorrectly designated Lactobacillus bifidus) and some related genera. J. gen. Microbiol. 21, 371.

Tittsler, R. P. (1930). The reduction of nitrates to nitrites by Salmonella pullorum and Salmonella gallinarum. J. Bact. 19, 261.

Wallace, G. I. \& Neave, S. L. (1927). The nitrite test as applied to bacterial cultures. J. Bact. 14, 37\%.

Woons, D. D. (1938). The reduction of nitrate to ammonia by Clostridium welchii. Biochem. $J .32,2000$.

ZoBELL, C. E. (1932). Factors influencing the reduction of nitrates and nitrites by bacteria in semisolid media. J. Bact. 24, 273.

ZuCKer, M. \& Nason, A. (1955). Hydroxylamine reductase from Neurospora crassa. In Methods in Enzymology, 2, 416. Ed. S. P. Colowick \& N. O. Kaplan. New York: Academic Press Inc.

\begin{abstract}
ADDENDUM
Clarke (1959) reported nitrate reduction by Lactobacillus brevis NCTC 2797. Dr M. Elisabeth Sharpe of the NIRD has confirmed that this strain reduces $\mathrm{n}$ itrates under appropriate conditions as described in this paper; but she has found that in fact this strain is not $L$. brevis but is $L$. fermenti as confirmed by nutritional and serological tests and growth temperatures.
\end{abstract}

